11

\title{
Электролюминесценция анодного оксида алюминия в кетонах
}

\author{
(ㄱ Д.С. Овеченко, А.П. Бойченко \\ Кубанский государственный университет, \\ 350040 Краснодар, Россия \\ "e-mail: bojchenco@yandex.ru
}

Поступила в редакцию 08.10.2019 г.

В окончательной редакции 08.10.2019 г.

Принята к публикации 21.10.2019 г.

\begin{abstract}
На сформированной электролизным окислением в дистиллированной воде пленке оксида алюминия продемонстрирована возможность генерации ее электролюминесценции в кетонах и родственных им соединениях, содержащих карбонильные группы. Для ацетона, циклогексанона, метилпирролидона, ацетилацетона, 4этилпропиофенона и 4-метоксипропиофенона установлено, что этот процесс протекает без электролиза перечисленных соединений. Показано, что при постоянных напряжении и температуре на яркостно-кинетические характеристики люминесценции оказывает существенное влияние сочетание следующих факторов: строение и элементный состав углеводородных радикалов кетонов, количество при этих радикалах карбонильных групп, толщина и структурная организация оксидных пленок $\mathrm{Al}_{2} \mathrm{O}_{3}$, на поверхности которых возможно локальное усиление напряженности электрического поля до величин порядка $10^{6} \mathrm{~V} / \mathrm{m}$, достаточных для инициирования и поддержания ионизационных процессов, ведущих к генерации светового излучения.
\end{abstract}

Ключевые слова: оксид алюминия, электролюминесценция, анодирование, дистиллированная вода, кетоны.

DOI: $10.21883 /$ OS.2020.02.48971.280-19

\section{Введение}

Сформированный электролизным окислением алюминия $(\mathrm{Al})$ нанопористый оксид этого металла $\left(\mathrm{Al}_{2} \mathrm{O}_{3}\right)$ является в настоящее время объектом всестороннего исследования, что связано с возможностью создания на его основе различных многофункциональных изделий и систем нано-, микро- и оптоэлектроники [1-4]. Как правило, $\mathrm{Al}_{2} \mathrm{O}_{3}$ названной структуры формируется в водных растворах слабых кислот, например щавелевой или лимонной $[5,6]$, а сопровождающее этот процесс явление электролюминесценции (ЭЛ) обычно привлекают для непосредственного контроля этапов зарождения, формирования и роста пор [7-9]. Однако вопрос о механизме явления, природе центров люминесценции остается дискуссионным и, как показывает библиографический анализ, наименее исследованным по сравнению с процессами анодирования $\mathrm{Al}$ в различных электролитах [6,10,11]. Именно последнее обстоятельство многообразия используемых видов электролитов, их концентраций, композиций, условий и режимов анодного окисления Al существенно осложняет интерпретацию и затрудняет сопоставление результатов исследований ЭЛ, так как в такой ситуации приходится учитывать многочисленные продукты электролиза растворенных в воде веществ, захватываемые образующимся $\mathrm{Al}_{2} \mathrm{O}_{3}$ [5,12]. Достаточно привести пример работы [6], где спектроскопия ЭЛ Al-анода проводилась в водных растворах щавелевой, лимонной и борной кислот разных концентраций, а также в смеси последней с гидроксидом аммония и этиленгликолем, поэтому в таких условиях анодирования максимумы спектров излучения охватывали ширину порядка $60 \mathrm{~nm}$. Для исключения влияния электролитных добавок на формирование анодного $\mathrm{Al}_{2} \mathrm{O}_{3}$ и упрощения интерпретации результатов исследований его ЭЛ нами была предложена методика анодирования Al (также и других металлов) в химически чистой воде (дистиллированной или деионизованной) $[13,14]$. Электронномикроскопическими исследованиями установлено, что формируемая в таких условиях структура из упорядоченных нанопор $\mathrm{Al}_{2} \mathrm{O}_{3}$ идентична образующимся при анодировании $\mathrm{Al}$ в водных растворах электролитов $[14,15]$. Несмотря на то, что предложенная методика позволила получать беспримесный $\mathrm{Al}_{2} \mathrm{O}_{3}$, к процессу его формирования оказалась очень чувствительна сопровождающая анодирование ЭЛ. На ее светимость существенно влиял как рост оксида, протекающего за счет электролиза воды, так и изменение температуры, происходящее в результате джоулева нагрева жидкости [16]. Поэтому для исследований основных характеристик ЭЛ (прежде всего яркостно-кинетических и спектрально-оптических) анодного $\mathrm{Al}_{2} \mathrm{O}_{3}$ необходим подбор электролита, не содержащего каких-либо примесей-добавок и не приводящий к дальнейшему росту оксида вследствие электролиза, сохраняя при этом эффективный токоперенос для поддержания люминесценции. Электролит с подобными свойствами был описан еще в 1964 г. М.И. Эйдельбергом, изучавшем безэлектролизный процесс генерации ЭЛ анодного $\mathrm{Al}_{2} \mathrm{O}_{3}$ в диэтилфталате [17-19]. В свете изложенных автором закономерностей об электронном механизме токопереноса и рекомбинационной природе возникновения ЭЛ нами было обращено внимание на наличие в молекуле названного вещества фрагментов из карбонильных групп (КНГ), обладающих, как известно, 
высокой электрической полярностью и значительным дипольным моментом (2.7 D), что делает их наиболее вероятными переносчиками электронов. Поскольку сочетание КНГ с различными углеводородными радикалами представляет целый класс органических соединений, относящихся к кетонам, то имеются основания предполагать безэлектролизное возникновение в них ЭЛ на анодном $\mathrm{Al}_{2} \mathrm{O}_{3}$. Настоящая работа посвящена проверке предположения и исследованию кинетических характеристик ЭЛ в различных кетонах, а также родственных их соединениях - лактамах и дикетонах (далее по тексту они будут называться обобщенным термином „кетоны“, как содержащие КНГ) при анодной поляризации Alэлектрода с $\mathrm{Al}_{2} \mathrm{O}_{3}$-покрытием, предварительно сформированном в дистиллированной воде.

\section{Эксперимент, его обсуждение и анализ результатов}

Для проведения исследований осуществлялся выбор кетонов по следующим критериям: а) нахождению в жидком агрегатном состоянии при стандартной температуре 298 K; б) наличию при одной КНГ углеводородных радикалов (УГВР), строение и элементный состав которых способны влиять на электронный перенос в такой группе и соответственно на характеристики ЭЛ; в) наличию у одного и того же УГВР нескольких КНГ. По перечисленным критериям были отобраны кетоны в последовательности увеличения молярной массы их УГВР $\left(M r_{\mathrm{CH}}\right)$ : ацетон $(A c)$, циклогексанон $(C h)$, метилпирролидон $(M p)$, ацетилацетон $(A c a c)$, 4-этилпропиофенон $(E p f)$ и 4-метоксипропиофенон $(M o p f)$. Все кетоны имели квалификацию „чда“ или „хч“ с содержанием основного вещества не менее 99.5\%. Предварительное формирование $\mathrm{Al}_{2} \mathrm{O}_{3}$ осуществлялось в течение $300 \mathrm{~s}$ на аноде из Al-проволоки (чистота металла $99.999 \%$ ) диаметром $0.5 \mathrm{~mm}$ в дистиллированной воде удельной электропроводностью $1.7 \cdot 10^{-4} \mathrm{~S} / \mathrm{m}$. Технология, режимы и условия анодно-электролизного оксидирования металла подробно описаны в $[14,16]$.

Регистрация ЭЛ в кетонах осуществлялась на экспериментальной установке, схему конструкции которой отражает рис. 1 . Как и ранее $[14,16]$, в ней использована двухэлектродная система с одинаковыми по длине и диаметру анодом из оксидированного Al и платиновым $(\mathrm{Pt})$ катодом. Расстояние между электродами составляло $12 \mathrm{~mm}$, а чистота Pt-проволоки - 99.999\%. Площадь рабочей поверхности электродов определялась по высоте анодированной части Al-проволоки $13 \pm 1 \mathrm{~mm}$. Ей соответствовал фиксированный в ходе экспериментов уровень жидкого кетона объемом $10 \mathrm{ml}$. При фиксированном на электродах внешнем напряжении $U=1.2 \mathrm{kV}$ и температуре электролита $298 \pm 0.5 \mathrm{~K}$ в ходе всего времени проведения эксперимента $800 \mathrm{~s}$ осуществлялось его перемешивание. По общепринятым методикам регистрировались изменения во времени $(t)$ величин

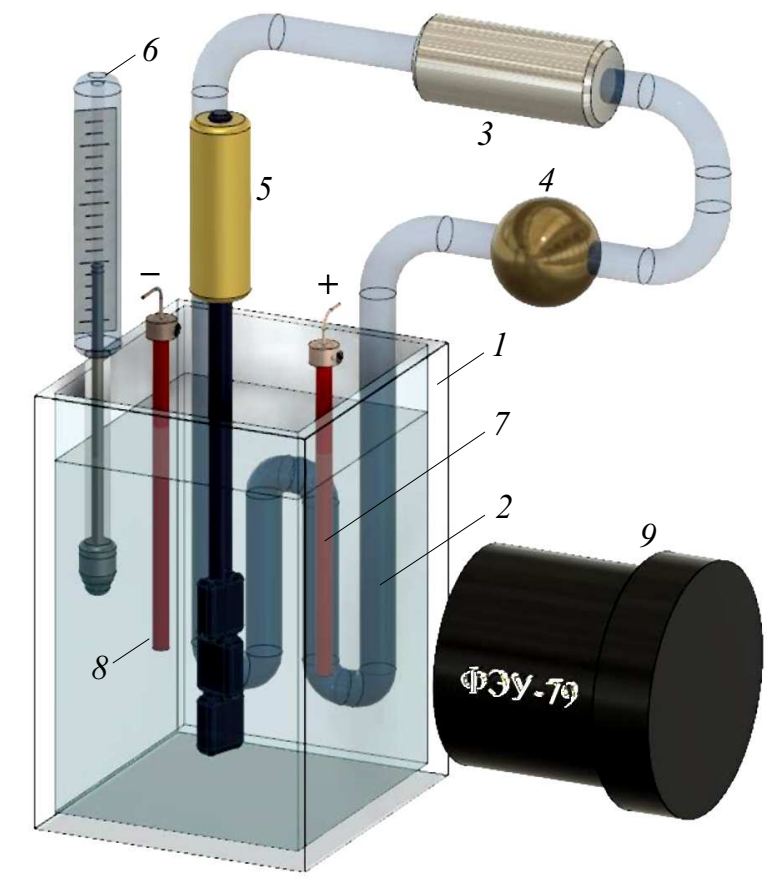

Рис. 1. Схема экспериментальной установки: 1 - кварцевая кювета (диапазон пропускания 190-2000 nm); 2 - змеевик с термостатом 3 и перистальтическим насосом 4; 5 - электромешалка; 6 - термометр; 7 - исследуемый анод; 8 Pt-катод; 9 - фотоэлектронный умножитель (ФЭУ-79).

плотности тока между электродами $(J)$ и светимости ЭЛ $(I)$.

Электрогенерированная люминесценция была зарегистрирована во всех кетонах на оксидированном Al-аноде и носила вспышечный характер в момент приложения напряжения. После вспышки наступал режим стационарного свечения меньшей интенсивности. Длительность вспышки $(\tau)$, ее пиковое значение светимости $\left(I_{f}\right)$ в момент времени $\left(t_{f}\right)$ при токе $\left(J_{f}\right)$ и стационарный уровень светимости ЭЛ $\left(I_{c}\right)$ существенно зависели от природы молекулы используемого кетона. Той же причиной определялось время запаздывания ЭЛ $\left(t_{z}\right)$ светимостью $\left(I_{z}\right)$ при токе $\left(J_{z}\right)$ относительно момента приложенного напряжения к электролитической системе. Усредненные по трем измерениям результаты оценки перечисленных параметров из кинетических зависимостей $I(t)$ и $J(t)$ представлены в табл. 1, а в табл. 2 - структурные формулы используемых кетонов.

Из табл. 1 видно, что анодный $\mathrm{Al}_{2} \mathrm{O}_{3}$ обнаруживает наиболее интенсивную ЭЛ в Acac, т.е. в кетоне, на УГВР молекулы которого приходится две КНГ, причем обладающие повышенной подвижностью (кето-енольная таутомерия). Поэтому для такой молекулы очень высока вероятность электронного переноса, чем и объясняется протекание через Acac наибольшей плотности тока по сравнению с другими кетонами и, как следствие, наибольшая светимость ЭЛ. Подобный эффект повышенного токопереноса за счет усиления электронной плот- 
Таблица 1. Результаты обработки кинетических зависимостей $I(t)$ и $J(t)$ в кетонах для анодного $\mathrm{Al}_{2} \mathrm{O}_{3}$

\begin{tabular}{l|c|c|c|c|c|c}
\hline $\begin{array}{c}\text { Кетоны и } \\
\text { регистриуемые } \\
\text { параметры ЭЛ }\end{array}$ & Ac & Ch & Mp & Acac & Epf & Mopf \\
\hline$M r_{\mathrm{CH}}, \mathrm{g} / \mathrm{mol}$ & 30.07 & 70.14 & 71.12 & 72.12 & 134.21 & 136.19 \\
$t_{z}, \mathrm{~s}$ & $3.0 \pm 0.4$ & $5 \pm 1$ & $2.0 \pm 0.3$ & $2.2 \pm 0.4$ & $1.8 \pm 0.2$ & $2.2 \pm 0.4$ \\
$t_{f}, \mathrm{~s}$ & $14 \pm 1$ & $36 \pm 4$ & $20 \pm 2$ & $14 \pm 1$ & $140 \pm 11$ & $140 \pm 11$ \\
$\tau, \mathrm{s}$ & $50 \pm 3$ & $230 \pm 14$ & $430 \pm 60$ & $85 \pm 13$ & $250 \pm 36$ & $380 \pm 60$ \\
$I_{z}, 10^{-5} \mathrm{~lm} / \mathrm{m}^{2}$ & $17.5 \pm 1.7$ & $4.0 \pm 0.3$ & $47 \pm 3$ & $78 \pm 5$ & $3.9 \pm 0.3$ & $16.4 \pm 1.5$ \\
$I_{f}, 10^{-5} 1 \mathrm{~m} / \mathrm{m}^{2}$ & $43 \pm 4$ & $12.3 \pm 1.3$ & $82 \pm 8$ & $205 \pm 30$ & $32 \pm 4$ & $56 \pm 8$ \\
$I_{c}, 10^{-5} 1 \mathrm{~m} / \mathrm{m}^{2}$ & $2.6 \pm 0.3$ & $1.5 \pm 0.2$ & $19.1 \pm 2.5$ & $88 \pm 11$ & $26 \pm 3$ & $32 \pm 3$ \\
$J_{z}, \mathrm{~A} / \mathrm{m}^{2}$ & $9.5 \pm 1.0$ & $7.1 \pm 0.7$ & $66 \pm 7$ & $86 \pm 9$ & $13 \pm 1$ & $13.6 \pm 1.4$ \\
$J_{f}, \mathrm{~A} / \mathrm{m}^{2}$ & $7.1 \pm 0.7$ & $5.8 \pm 0.6$ & $60 \pm 6$ & $83 \pm 8$ & $12 \pm 1$ & $12 \pm 1$
\end{tabular}

ности на атоме кислорода КНГ возможен при наличии у такой группы дополнительных электронов. Их поставщиком может являться, например, неподеленная электронная пара атома азота, замещающего углерод в УГВР. Поэтому в $M p$ для анодного $\mathrm{Al}_{2} \mathrm{O}_{3}$ также отмечаются высокие величины светимости его ЭЛ и протекающего через электролит тока. Отсутствие электрон-донорного атома при КНГ существенно уменьшает величины названных параметров, что и наблюдается, в частности, для $A c$ и $C h$. Этому также способствует их симметричный УГВР. В случае ароматических кетонов - Epf и $M o p f$, содержащих в УГВР бензольное кольцо (табл. 2), наблюдается ряд особенностей ЭЛ. По сравнению с остальными кетонами разгорание люминесценции $\mathrm{Al}_{2} \mathrm{O}_{3}$ в них происходит с большим замедлением, что видно по данным $t_{f}$, составляющего $140 \mathrm{~s}$. При этом величины протекающих $J$ оказываются примерно в 6 раз меньше для $M p$ и Acac, но в 2 раза больше регистрируемых в $A c$ и $C h$. Однако светимости ЭЛ в каждом из ароматических кетонов различаются, особенно в момент зажигания и пика разгорания. Наблюдаемая закономерность очевидно связана не только с асимметрией УГВР их молекул, но и наличием в $M o p f$ атома кислорода (табл. 2), отделенного от КНГ бензольным кольцом. Это обеспечивает названному атому определенную подвижность, позволяя вносить свой вклад в перераспределение электронной плотности молекулы Mopf и таким образом влиять на электронный транспорт и светимость ЭЛ. Для всех кетонов, подвергшихся электротоковому воздействию в электролюминесцентной установке, была проведена ЯМР и оптическая спектроскопия (в диапазоне 190-700 nm), не выявившая каких-либо изменений в химическом составе веществ по сравнению с их контрольным вариантом.

Из совокупности полученных результатов и установленных закономерностей следует, что использованные в работе КНГ-содержащие соединения являются безэлектролизными переносчиками электронов, способствующими активации и поддержанию ЭЛ анодного $\mathrm{Al}_{2} \mathrm{O}_{3}$, на эффективность генерации которой влияют как строение и состав УГВР кетонов, так и количество КНГ в их молекулах (при постоянстве остальных факторов
Таблица 2. Структурные формулы использованных кетонов

\begin{tabular}{c|c}
\hline Аббревиатура кетона & Структурная формула \\
\hline$A c$ & \\
\hline Mp & \\
\hline Acac & \\
\hline Epf & \\
\hline & \\
\hline & \\
\hline
\end{tabular}

и условий). Однако вопрос о влиянии на яркостнокинетические характеристики ЭЛ структуры и толщины самого оксида остался открытым. Для ответа на него были проведены дополнительные исследования с $\mathrm{Al}_{2} \mathrm{O}_{3}$ покрытием, полученным при том же напряжении $1.2 \mathrm{kV}$, но разном времени анодирования $\left(t_{a}\right)$ Al-проволоки в дистиллированной воде: 100,300 и $1700 \mathrm{~s}$. Это соответствует толщинам покрытия порядка 2, 5 и $15 \mu \mathrm{m}$. Поскольку $\mathrm{Al}_{2} \mathrm{O}_{3}$ обнаруживает наибольшую светимость ЭЛ в Acac, то в названном кетоне осуществлялась регистрация кинетики люминесценции оксида совместно с протекающим через электролит током при условиях 

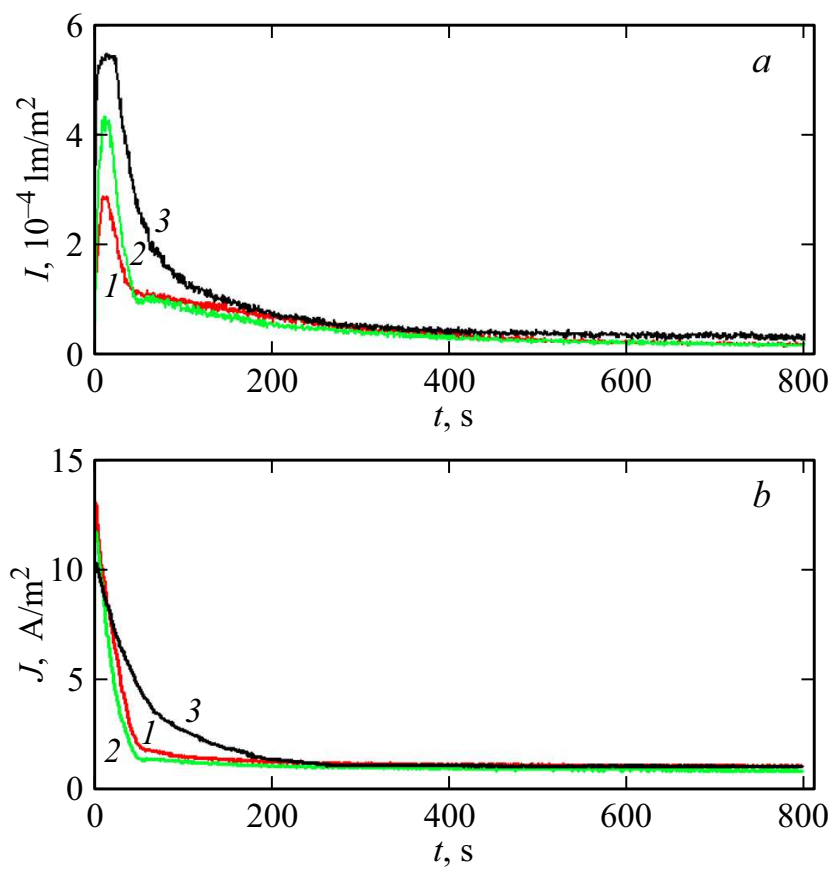

Рис. 2. Кинетические зависимости светимости $(a)$ и плотности тока $(b)$ в $A c$ для анодного $\mathrm{Al}_{2} \mathrm{O}_{3}$ толщиной $2 \mu \mathrm{m}-1$; $5 \mu \mathrm{m}-2 ; 15 \mu \mathrm{m}-3$.

и режимах, соответствующих описанным в предыдущем эксперименте. Для сравнения полученных результатов на Acac аналогичные исследования были проведены с простейшим представителем кетонов - $A c$. С целью установления возможного влияния эмиссионных и электрон-транспортных процессов на морфологию структуры анодного $\mathrm{Al}_{2} \mathrm{O}_{3}$ проводилась его визуализация при 10000-кратном увеличении растрового электронного микроскопа (РЭМ). Результаты измерений перечисленных параметров и РЭМ-изображений структуры $\mathrm{Al}_{2} \mathrm{O}_{3}$ представлены на рис. 2-6.

По рис. 2, $a$ и 3, $a$ видно, что кинетические зависимости $I(t)$ качественно идентичны как между собой, так и ранее опубликованным для $\mathrm{Al}_{2} \mathrm{O}_{3}$ в диэтилфталате [1719]. Это подкрепляет вывод об определяющей роли КНГ в генерации и поддержании ЭЛ. Однако между Ac и Асас количественные значения светимости ЭЛ разнятся на порядок, а $I_{f}$ люминесценции $\mathrm{Al}_{2} \mathrm{O}_{3}$ в них имеет обратную зависимость от толщины оксидной пленки. Так, в Ac наибольшая величина этого параметра зарегистрирована у образца с $\mathrm{Al}_{2} \mathrm{O}_{3}$ толщиной $15 \mu \mathrm{m}$, а в Acac $-2 \mu \mathrm{m}$. При этом выход люминесценции на стационарный уровень для всех образцов в $A c$ наступает на 200-й секунде, тогда как в Acac - на 400-й. В случае $J(t)$ также проявляется зависимость величины этого параметра от толщины $\mathrm{Al}_{2} \mathrm{O}_{3}$ и разновидности кетона (рис. $2, b$ и $3, b)$. Однако начальная величина тока в электролитической системе с $2 \mu$ m пленкой оксида оказывается всегда больше такового с пленкой толщиной $15 \mu \mathrm{m}$ в обоих кетонах, что объясняется проявлением в разной степени барьерных свойств оксида к проходящим через него электронам. При этом различия $J(t)$ для разнотолщинных пленок выражены сильнее в Acac, чем в Ac. Для последнего кетона характерен резкий спад тока, совпадающий по длительности со вспышкой ЭЛ, тогда как в Acac такое совпадение отсутствует. Объяснить большинство выявленных закономерностей позволяют РЭМ-изображения разнотолщинных пленок $\mathrm{Al}_{2} \mathrm{O}_{3}$, проявляющих ЭЛ в кетонах.

Судя по рис. 4-6, наибольшие морфологические изменения структуры пленок всех толщин происходят в Асас (рис. 6) и не наблюдаются в $A c$ для $\mathrm{Al}_{2} \mathrm{O}_{3}$ толщины 5 и $15 \mu \mathrm{m}$ (рис. $5, b$ и 5,c). Для пленки $2 \mu \mathrm{m}$ в последнем кетоне характерно порообразование в местах, где на исходном образце имелись упорядоченные неоднородности поверхности оксида (на рис. 4, $a$ два из таких участков выделены рамками). Очевидно, что при его 100секундном формировании в дистиллированной воде названные неоднородности образуют систему из закрытых пор диаметром, не превышающим сотни нанометров, а каждой открытой поре того же диаметра соответствует полусферический выступ высотой порядка $250 \mathrm{~nm}$, на вершине которого она располагается. Предположительно процесс электротоковой „распечатки“ закрытых пор в Ac протекает за время $\sim 50 \mathrm{~s}$, соответствующее времени резкого спада тока и длительности вспышки ЭЛ. В Асас этот процесс протекает интенсивнее и возрастает от толщины $\mathrm{Al}_{2} \mathrm{O}_{3} 2 \mu \mathrm{m}$ к $15 \mu \mathrm{m}$. Для последнего случая характерно образование крупных пор, средний диаметр которых составляет $290 \mathrm{~nm}$. Кроме того, в результате этого процесса отмечаются разрушение выступов и
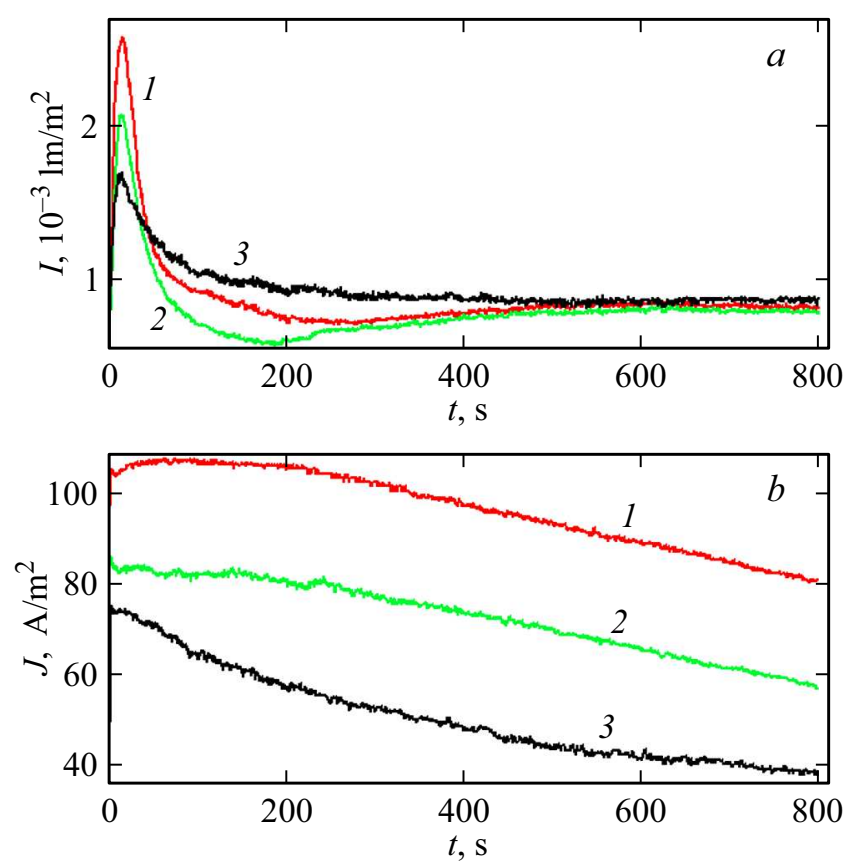

Рис. 3. Кинетические зависимости светимости (a) и плотности тока $(b)$ в Acac для анодного $\mathrm{Al}_{2} \mathrm{O}_{3}$ толщиной $2 \mu \mathrm{m}-1$; $5 \mu \mathrm{m}-2 ; 15 \mu \mathrm{m}-3$. 

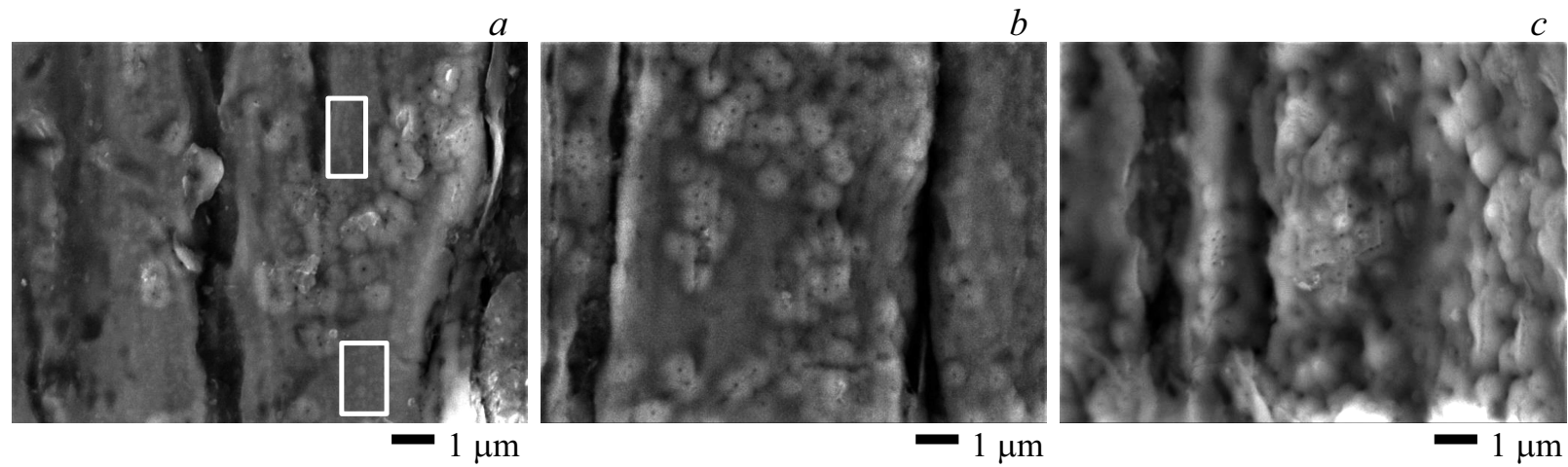

Рис. 4. РЭМ-изображения контрольных образцов анодного $\mathrm{Al}_{2} \mathrm{O}_{3}$, сформированного в дистиллированной воде за время: $100 \mathrm{~s}(a)$, $300 \mathrm{~s}(b)$ и $1700 \mathrm{~s}(c)$.
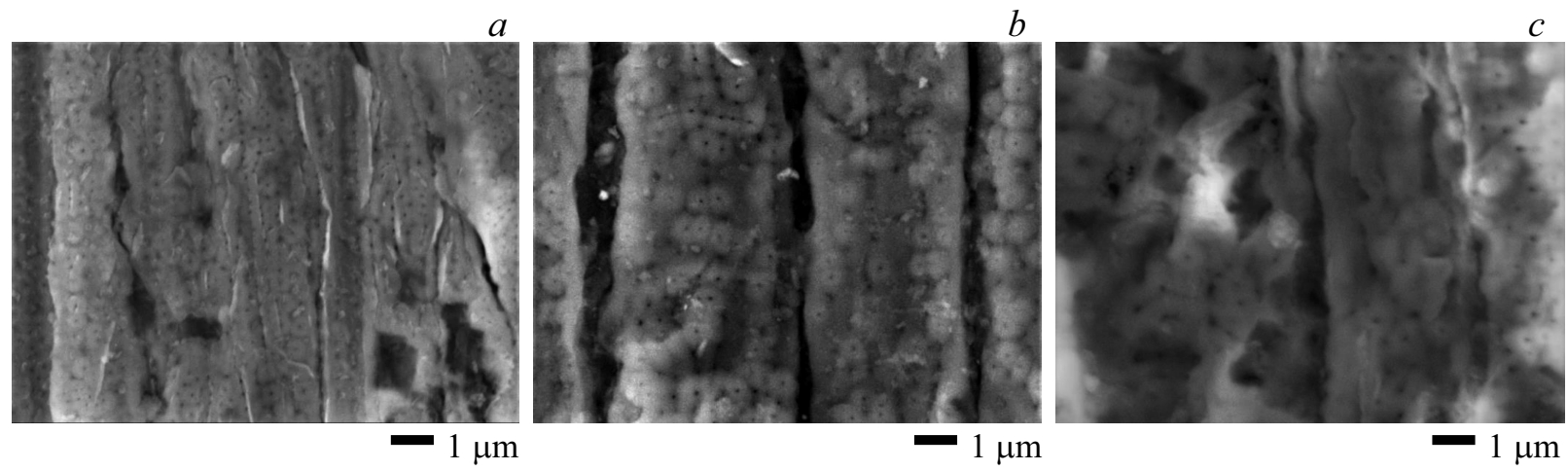

Рис. 5. РЭМ-изображения анодного $\mathrm{Al}_{2} \mathrm{O}_{3}$ после регистрации ЭЛ в Ас для образцов, сформированных в дистиллированной воде за время $100 \mathrm{~s}(a), 300 \mathrm{~s}(b)$ и $1700 \mathrm{~s}(c)$.
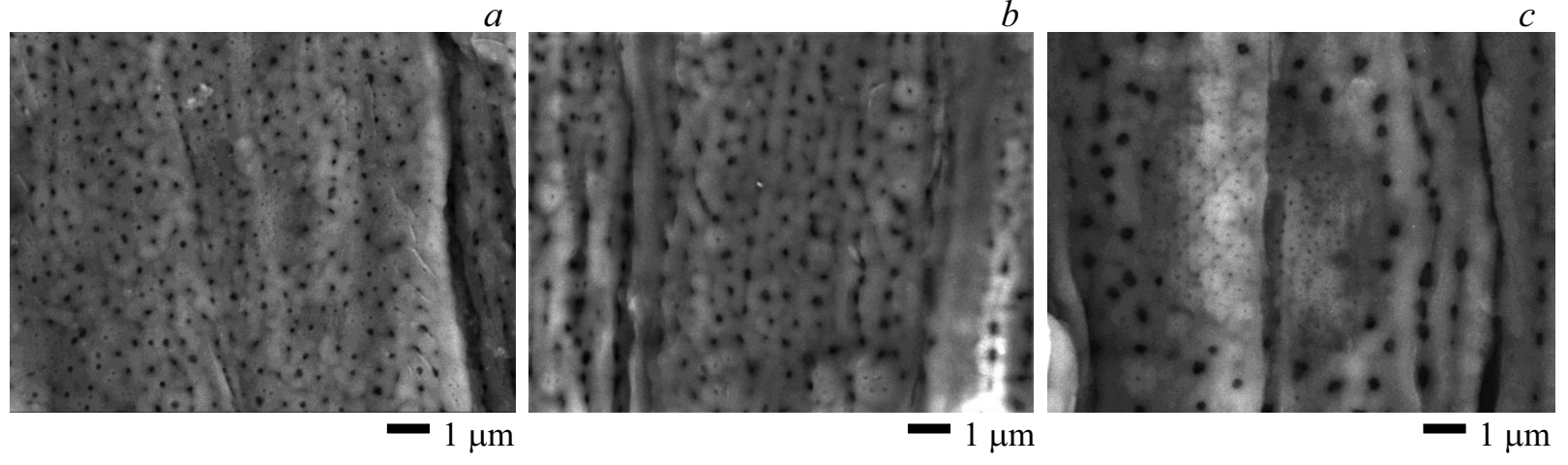

Рис. 6. РЭМ-изображения анодного $\mathrm{Al}_{2} \mathrm{O}_{3}$ после регистрации ЭЛ в Асас для образцов, сформированных в дистиллированной воде за время $100 \mathrm{~s}(a), 300 \mathrm{~s}(b)$ и $1700 \mathrm{~s}(c)$.

тенденция к сглаживанию поверхности оксидной пленки (рис. 5, $a$ и 6). Пленки $\mathrm{Al}_{2} \mathrm{O}_{3}$ толщиной 5 и $15 \mu$ т оказываются более устойчивыми к электронно-транспортным процессам в Ac. Неоднородность поверхности их структуры сохраняется, как и полусферические выступы с открытыми порами. На наш взгляд, именно эти элементы поверхности оказывают существенное влияние на светимость ЭЛ, особенно ее вспышечных характеристик, так как в силу своей геометрии способны концентрировать электрическое поле, локальная напряженность $\left(E_{\max }\right)$ которого может существенно превышать его среднее значение в $\mathrm{Al}_{2} \mathrm{O}_{3}(E)$. Оценим величины этих полей для каждой из толщин оксидных пленок, учтя тот факт, что вместе с примыкающим к пленкам жидким кетономдиэлектриком они образуют систему двухслойного конденсатора. Поскольку его обкладки имеют цилиндрическую форму одинакового радиуса $(R)$, который много меньше межэлектродного расстояния, то выражение для 
Таблица 3. Результаты измерений вспышечных характеристик ЭЛ и оценки напряженности электрического поля на неоднородностях пористой структуры $\mathrm{Al}_{2} \mathrm{O}_{3}$ в кетонах, сформированного при разном времени анодирования в дистиллированной воде

\begin{tabular}{|c|c|c|c|c|c|c|c|}
\hline$t_{a}, \mathrm{~s}$ & $R_{s}, \mathrm{~nm}$ & $R_{0}, \mathrm{~nm}$ & $L, \mathrm{~nm}$ & $d, \mathrm{~nm}$ & $I_{f}, 10^{-5} \mathrm{~lm} / \mathrm{m}^{2}$ & $E_{\max }, 10^{6} \mathrm{~V} / \mathrm{m}$ & $E, 10^{5} \mathrm{~V} / \mathrm{m}$ \\
\hline \multicolumn{8}{|c|}{$A c\left(\varepsilon_{2}=20.7\right)$} \\
\hline 100 & 80 & 50 & 250 & 100 & 28.5 & 1.1 & \multirow{3}{*}{4.4} \\
\hline 300 & 180 & 60 & 330 & 120 & 43 & 2.3 & \\
\hline 1700 & 230 & 90 & 450 & 170 & 54.5 & 3.4 & \\
\hline \multicolumn{8}{|c|}{$\operatorname{Acac}\left(\varepsilon_{2}=25.7\right)$} \\
\hline 100 & 160 & 90 & 330 & 120 & 255 & 5.8 & \multirow{3}{*}{4.7} \\
\hline 300 & 200 & 110 & 440 & 165 & 205 & 4.6 & \\
\hline 1700 & 260 & 220 & 520 & 290 & 169 & 2.6 & \\
\hline
\end{tabular}

$E$ примет вид

$$
E=\frac{U \varepsilon_{2}}{2 R\left(\varepsilon_{1}+\varepsilon_{2}\right) \ln \left[\left(d_{1}+d_{2}+2\right) R^{-1}\right]},
$$

где $d_{1}$ и $d_{2}$ - толщины пленки $\mathrm{Al}_{2} \mathrm{O}_{3}$ и жидкого диэлектрика с диэлектрическими проницаемостями $\varepsilon_{1}=8$ [20] и $\varepsilon_{2}$ соответственно. Так как в рассматриваемом случае $d_{1} \ll d_{2}$, то (1) можно записать в виде

$$
E=\frac{U \varepsilon_{2}}{2 R\left(\varepsilon_{1}+\varepsilon_{2}\right) \ln \left[\left(d_{2}+2\right) R^{-1}\right]} .
$$

Тогда

$$
E_{\max }=K_{g} E=\frac{R_{s}^{2}\left[1-\cos \left(\arcsin \left(L\left(2 R_{s}\right)^{-1}\right)\right)\right]}{R_{0}^{2}\left[1-\cos \left(\arcsin \left(d\left(2 R_{0}\right)^{-1}\right)\right)\right]} E,
$$

где $K_{g}$ - коэффициент локального усиления электрического поля нанопористой структурой пленки $\mathrm{Al}_{2} \mathrm{O}_{3}$, предложенный в [21]; $R_{s}$ - радиус сферического сегмента элементарной ячейки с порой диаметром $d ; R_{0}-$ радиус сферического сегмента дна поры; $L-$ расстояние между центрами пор. Графическое представление перечисленных параметров приведено авторами [21] на рис. 1. Результаты расчетов для $E$ и $E_{\max }$ при внешнем напряжении $1.2 \mathrm{kV}$ со вспышечными характеристиками ЭЛ и диэлектрическими проницаемостями кетонов представлены в табл. 3.

Из данных табл. 3 видна хорошая корреляция величин $E_{\max }$ с экспериментальными данными пиковых характеристик $I_{f}$ ЭЛ разнотолщинного $\mathrm{Al}_{2} \mathrm{O}_{3}$ в $A c$ и Acac. Важным следствием этой корреляции является четко прослеживаемая закономерность: с ростом напряженности $E_{\max }$ увеличивается светимость ЭЛ в обоих кетонах. Таким образом, не только наличие оксидной пленки, но и ее структурная организация являются факторами, определяющими яркостные характеристики электрогенерированной люминесценции в кетонах. Этот вывод согласуется с недавно полученными результатами по ЭЛ Al и Та при их анодировании в спиртах [22]. Стоит отметить, что величина средней напряженности электрического поля в оксидной пленке $E$, рассчитанная с учетом ее контакта с Ac и Acac, оказывается на три порядка меньше полученной в [21], поскольку авторами использовался водный раствор слабо диссоциирующей (щавелевой) кислоты и не учитывался образуемый им слой, примыкающий к $\mathrm{Al}_{2} \mathrm{O}_{3}$, что ведет к перераспределению приложенного напряжения и соответственно напряженности поля между слоями. Однако рассчитанные нами величины $E_{\max }$ с учетом предложенного в работе [21] параметра $K_{g}$ оказываются достаточными для инициирования и поддержания ионизационных процессов, ведущих к генерации светового излучения.

\section{Заключение и выводы}

В настоящее время кетоны преимущественно используются в качестве вспомогательных веществ (например, $A c)$ при подготовке $\mathrm{Al}$ к анодированию [5,23]. Имеются публикации по применению Асас и его соединений с металлами (ацетилацетонаты) в виде добавок к водным растворам для химического преобразования пленок $\mathrm{Al}_{2} \mathrm{O}_{3}$ на анодированном $\mathrm{Al}$ [24,25], а также в неводных электролитах для анодирования других металлов [25]. Как показано в настоящей работе, кетоны и их родственные соединения могут быть использованы не только в качестве самостоятельных КНГ-содержащих электролитов для безэлектролизного преобразования пленок $\mathrm{Al}_{2} \mathrm{O}_{3}$, но и для исследований электрон-транспортных процессов через такие пленки, приводящих к генерации ЭЛ. Причем интерпретация результатов этих исследований оказывается свободной от учета каких-либо добавок или продуктов электролиза в исходном электролите.

Обобщая результаты проведенных исследований, можно сделать по ним следующие выводы.

1. Сформированная электролизным окислением в дистиллированной воде пленка $\mathrm{Al}_{2} \mathrm{O}_{3}$ толщиной от 2 
до $15 \mu \mathrm{m}$ обнаруживает электрогенерированную люминесценцию в кетонах и родственных им соединениях, содержащих КНГ. В таких соединениях, как $A c, C h, M p$, $A c a c, E p f$ и $M o p f$, этот процесс протекает без их электролиза.

2. При постоянных напряжении и температуре на яркостно-кинетические характеристики ЭЛ оказывает существенное влияние сочетание следующих факторов: строение и элементный состав УГВР кетонов, количество при этих радикалах КНГ, толщина и структурная организация пленок $\mathrm{Al}_{2} \mathrm{O}_{3}$. Причем неоднородности и морфологические особенности нанопористой структуры пленок приводят к локальному усилению напряженности электрического поля, достигающего значений порядка $10^{6} \mathrm{~V} / \mathrm{m}$, которого достаточно для инициирования и поддержания ионизационных процессов, ведущих к генерации светового излучения.

В заключение отметим, что при отсутствии оксидных покрытий на Al-анодах не было обнаружено какого-либо светового излучения ни в одном из использованных в настоящей работе кетонов.

\section{Финансирование работы}

Исследование выполнено при финансовой поддержке РФФИ в рамках научного проекта № 19-32-90112.

\section{Конфликт интересов}

Авторы заявляют, что у них нет конфликта интересов.

\section{Список литературы}

[1] Lazarouk S., Katsouba S., Leshok A., Demianovich A., Stanovski V., Voitech S., Vysotski V., Ponomar V. // Microelectron. Eng. 2000. V. 50. N 1-4. P. 321.

[2] Katsouba S., Jaguiro P., Lazarouk S., Smirnov A. // Physica E. 2009. V. 41. P. 931.

[3] Sulka G.D., Hnida K. // Nanotechnology. 2012. V. 23. P. 075303.

[4] Lee W., Park S.J. // Chem. Rev. 2014. V. 114. P. 7487. doi.org/10.1021/cr500002z

[5] Ilango M.S., Mutalikdesai A., Ramasesha S. // J. Chem. Sci. 2016. V. 128. N 1. P. 153. doi 10.1007/s12039-015-1006-8

[6] Гриднев А.Е., Чернышев В.В. // Вестник ВГУ, Сер. Физика. Математика. 2005. № 2. C. 8.

[7] Zeković Lj.D, Urošević V.V. // Thin Solid Films. 1981. V. 78. N 3. P. 279. doi 10.1016/0040-6090(89)90594-4

[8] Zeković Lj.D., Urošević V.V. // Thin Solid Films. 1981. V. 86. N 4. P. 347. doi 10.1016/0040-6090(81)90342-4

[9] Zeković Lj.D., Urošević V.V., Jovanić B. // Appl. Surface Sci. 1982. V. $11-12$. P. 90.

[10] Wielage B., Alisch G., Lampke Th., Nickel D. // Key Engin. Mater. 2008. V. 384. P. 263.

[11] Keen Mc. // Fluorinated coatings and finishes handbook. 2006. P. 99. doi 10.1016/B978-081551522-7.50011-X

[12] Вихарев А.В., Вихарев А.А. // Ползуновский вестник. 2010. № 3. C. 204.
[13] Овеченко Д.С., Бойченко А.П. // Научный альманах. 2019. № 2-2(52). C. 75. doi 10.17117/na.2019.02.02.075

[14] Овеченко Д.С., Бойченко А.П. // Письма в ЖТФ. 2019. T. 45. B. 10. C. 31. doi 10.21883/PJTF.2019.10.47753.17723; Ovechenko D.S., Boychenko A.P. // Techn. Phys. Lett. 2019. V. 45. N 5. P. 503. doi 10.1134/S1063785019050250

[15] Lisenkov A.D., Poznyak S.K., Zheludkevich M.L., Ferreiraa M. // J. Electrochem. Soc. 2016. № 163(7). P. 364. doi $10.1149 / 2.0881607$ jes

[16] Овеченко Д.С., Бойченко А.П. // Экологический вестник научных центров ЧЭС. 2019. Т. 16. № 2. С. 59. doi 10.31429/vestnik-16-2-59-67

[17] Эйдельберг М.И. // Опт. и спектр. 1964. Т. 16. В. 1. С. 97.

[18] Эйдельберг М.И. // Опт. и спектр. 1964. Т. 17. В. 2. С. 244.

[19] Эйдельберг М.И. // Опт. и спектр. 1964. Т. 17. В. 3. С. 426.

[20] Горох Г.Г., Фейзуллаев Р.Э., Кошин Ю.А. // Актуальные проблемы твердотельной электроники и микроэлектроники: 7 международная научно-техническая конференция. Таганрог, 2000. С. 252.

[21] Лазарук С.К., Качуба П.С., Лешок А.А., Высочкий В.Б. // ЖТФ. 2015. Т. 85. В. 9. С. 86.

[22] Овеченко Д.С., Бойченко А.П. // Экологический вестник научных центров ЧЭС. 2019. Т. 16. № 3. С. 68. doi 10.31429/vestnik-16-3-68-75

[23] Stojadinović S., Vasilić R., Kasalica B., Belča I., Zeković L. // Electrodeposition and Surface Finishing. 2014. Part of the Modern Aspects of Electrochemistry book series (MAOE, vol. 57). P. 241. doi 10.1007/978-1-4939-0289-7_5

[24] Barkey D.P. Patent US № US009689064B2, 2017.

[25] Sorachon Yoriya. Materials Challenges and Testing for Manufacturing, Mobility, Biomedical Application and Climate. Springer, 2014. P. 107. doi 10.1007/978-3-31911340-1_111 